"Chronic aneurisms of the heart," he continues, " are almost always the result of chronic myocarditis. Fatty degeneration seems to be an occasional though extremely rare cause of this condition." He nowhere calls direct attention to an atheromatous condition of the coronary arteries as a cause. Constantin Paul speaks of a case under his observation where there was an atheromatous condition of the aorta and he supposed this to be the starting point in the case that he reports.

Dr. Mary Putnam Jacobi says (in Wood's Reference Handbook): "The essential cause of heartaneurism is thus identical with arterial aneurism, the lesion of structure is however different as might be expected from the difference of tissue in the heart and arteries. In the latter, that is, the arteries, nontraumatic aneurism nearly always depends on atheroma; in the former upon fibroid disease the result of chronic interstitial myocarditis."

In the present case, I think, there is no doubt that the starting point was the diminished calibre of the left coronary artery by this atheromatous condition diminishing the supply of nutriment to the corresponding tissue and thus producing the extreme thin. ness of the walls in the part supplied by the artery. The clot of blood was probably the result of the incapacity of the left ventricle to completely contract and expel its contents and probably occurred in part at the time of his acute sickness about 9 weeks before death.

The presence of this clot of blood fully explained the characteristic sound which I clearly recognized at the first and which I described as though the ven. tricle contracted on a pledget of wool.

\section{COCKLE-BUR REMOVED BY TRACHEOTOMY FROM THE LARYNX.}

Read before the Medical Society of the District of Columbia, May 4, 1887 .

BY J. FORD THOMPSON, M.D.,

OF WASHINGTON, D. C.

W. D., white, æt. I6, admitted to Children's Hospital, 8.30 P.M., April 20, I 887 . He was brought to the Hospital by Dr. Stone, of Brightwood. He was playing ball, having a cockle-bur in his mouth, which he drew into his larynx by a deep inspiration following violent exertion. Violent coughing ensued, accompanied by bloody expectoration, total aphonia, and considerable dyspncea. Dr. Stone saw him immedtately after the accident, but was unable to remove the bur with the instruments at hand. Concluding that tracheotomy was called for he brought the boy to the hospital, having telephoned me to be on hand to operate.

When I saw him he was breathing so quietly and easily that I doubted the presence of any foreign substance in the wind-pipe, although there was tenderness about the larynx and he would not make an effort to talk. I passed an oesopheal bougie down to the stomach without restult. I then passed my index finger into the larynx and readily detected the bur.
Free emesis followed, but no relief. Considering it a case for extracting by the aid of the laryngoscope, and not having the necessary instruments in the hospital at the time, I determined to take him to Dr. C. E. Hagner's office. Dr. Hagner and Dr. Murray, who happened to be present, examined him and readily saw the bur. Dr. H. made repeated efforts to extract it but failed. He was sent back to the hospital with instructions to watch him closely during the night and to administer bromide of potassium, and apply wet cloths to the neck.

April 2 I. IO.30 A.M. Had passed a fairly comfortable night; refused to take any nourishment. Present Drs. Hagner, Triplett, Stone, Cutter, Mundel and the house assistants. Dr. Hagner used the mirror but did not see the body; considerable mucus in larynx. He was still breathing easily, with no cough. I decided to open the trachea at once. After chloroform was administered, I cut through the two upper rings of the trachea, and as this opening was not sufficient, I extended it through the body of the cricord. I inserted a loop of silk to each side of the cartilage to keep the wound open, as they were less in the way than the retractors. I made every effort to detect and grasp the body with tracheal forceps but failed. I then introduced the index finger of my left hand into the larynx and readily felt the bur, which was to the left side, probably in the ventricle. I introduced the curved forceps through the wound and dislodged the body, and with the aid of the fingers in the larynx pushed it upwards and extracted it through the mouth. I inserted a tube which was left in for 24 hours.

April 22.-Rested well during night. 'Temp. $99^{\circ}$. Tube taken out.

April 23.-Doing well. Lower part of wound healed by first intention, the tube opening left to heal by granulation.

April 24.- Speaks in his natural tone; appetite good.

April 30.-Discharged cured.

I would call especial attention to the ease and thoroughness of exploration of the larynx by the fingers as shown in this case. I scarcely believed it possible before to do it so readily and so satifactorily.

Other cases reported are:

1. Cockle-bur in larynx. Drs. Brown and Van Note. S. C., æt. I I, running across a field, fell; cockle-bur flew in mouth and into larynx. Respiration labored and voice of a croupy whisper. Introduced probang into stomach to be sure it was not in œsophagus. Could not remove with forceps so 48 hours after accident performed laryngotomy. Bur in right ventricle. Recovery.

2. Cockle bur in larynx. S. T. Armstrong, M.D., Asst. Surg. U. S. Marine Hospt. Service, Memphis, Tenn. S. Miller, colored, xt. I I, while running in a field with mouth open inhaled cockle-bur which was blown by wind. Oct. r4. Breathing difficult, deglutition painful. Palliative means used by a physician of Memphis. Dr. A. saw him in consultation at i6. Curved forceps used but failed. They were then introduced through incision but failed to dislodge or grasp it. Finger introduced in mouth 
and with aid of forceps through incisions brought out through mouth.

3. Cockle-bur in larynx. Geo. W. Norman, Sweet Mills, Ky., Oct. 24, 1879. Bur lodged in larynx by inhalation during some exertion. Free vomiting and coughing failed to dislodge it. Tracheotomy was performed next morning and wound left open 6 days. At the end of that time it was coughed up. Recovery.

\section{MEDICAL PROGRESS.}

Artificial and Combined Drainage of the Bladder, Kidneys, and Uterus Through the Vagina, with and without Gradisated Pressure. -Dr. Nathan Bozeman, of New York, read a paper on this subject in the Section on Gynecology of the IXth International Medical Congress. He described an instrument which he had devised recently. This draws the uterine away from the mucous membrane, and in the most perfect manner. $\mathrm{He}$ has also been able to combine in the same instrument drainage with the dilatation of the cicatricial tissue of the vagina. The form of the instruments which concerns us here is intended for drainage alone, and I have called them intra-vaginal and vulvo-vaginal drainage-supports. The intra-vaginal instrument is applicable in most cases to all positions of the body. The vulvo-vaginal form is suited to the recumbent position, and to cases where the perineum is lacerated. These can be introduced and removed by the patient when necessary. They are small and simple, free from angles and sharp bodies, are readily kept clean, and excite no discomfort or irritation of the vagina. They do not press on the rectum or vagina, nor do they interfere with locomotion.

The author closed his paper with the following conclusions :

I. The importance of completion of the operation for fistula has not been duly appreciated. This forms, in many cases, the principal difficulty in the successful performance of the operation for the closure of the fistular opening. In other cases, when the fistula is cured, but the complications left without treatment, they lead sooner or later to the death or suffering of the patient. The greatest care should therefore be taken to discover and remove them.

2. Kolpokleisis, occlusion of the os uteri, and incision of the cervix in the bladder or rectum, are unjustifiable operations. They destroy the functions of the generative organs, lead to cystitis, then form venereal and vesicular calculi, pyelitis, and other diseases. Moreover, they are unnecessary. By means of the preparatory treatment of the complication by the aid of my button-suture and my dilating speculum, I have been able to overcome all the difficulties which have been described as indications for operation.

3. The association of combined drainage in the dilatation of the vagina is a great improvement.
The inconvenience and evil effects of incontinence of urine are thereby lessened, and the duration of the treatment shortened by the more rapid healing of the incisions and the formation of less cicatricial material in the reparative process.

4. We now propose a means of palliating the suffering due to incontinence of urine in a small proportion of cases of fistula which are incurable by this method-even the dangerous one of kolpokleisis. I believe that some form of drainage may be instituted in every case, and the patient may be thus restored to enjoy life and the performance of its duties.

5. The possession of a system of combined drainage will widen the scope of the operation of kolpocystotomy, done for cystitis, by removing the evils of incontinence of urine, now the chief objection to its performance.

6. Finally, I think the operation which I call kolpourethro-cystotomy, followed by the exploration and treatment of the disease of the uterus and pelvis of the kidney, has a brilliant future before it. In the treatment of pyelitis, renal calculi, and obstruction of the ureters, it will restrict within narrow limits the operation of nevhrotomy and nephrectomy.

Dr. Grailey Hewett, of London, said: The paper just read had shown decided advance in this line of thought. Conservative surgery, in this our day, seems to be running a race with operative surgery. $\mathrm{He}$ endorsed the views of the essayist thoroughly-Medical Record, Sept. 10, 1887.

Galvanism in Pruritus Vulve.-Dr. H. von CAMPE, of Hanover, reports the results of a mode of treatment to which his attention was directed by a communication from $W$. Blackwood, which first appeared in the Polyclinic, I885. Von Campe was consulted in the beginning of August, 1885 , by a woman aged 53 , who was suffering from an intense itching of the vulva, groin, perineum and anus. The patient had always been healthy until $2 \frac{1}{2}$ years after an abortion, when she had irregular discharges of blood from the uterus, to remedy which the organ was curetted. After the curetting the discharges of blood never recurred, but she suffered from a profuse acrid discharge. In spite of various modes of treatment the condition was not remedied, but itching began in the vagina and extended gradually over the mons veneris, groin, perineum and anus. The patient consulted various physicians, one of whom even excised portions of the integument where the irritation was most intolerable, but no measure of treatment resulted in more than slight temporary relief. She had long employed injections and solutions of carbolic acid and sugar of lead, but with only slight effect.

After trying salicylic ointments and cocaine, which alleviated the distress for only a few hours, von Campe resorted to galvanism on September 2 I, using at first a current from 6 elements with the anode applied to the vulva and the cathode to the affected portions of the integument. The sittings lasted 10 minutes. A weak solution of carbolic acid was also prescribed, to be employed night and morning. Two days later the patient reported that the pruritus left 